\title{
Contemporary techniques and safety of cardiovascular procedures in the surgical management of renal cell carcinoma with tumor thrombus
}

Jordon G. Lubahn, BS, ${ }^{a}$ Arthur I. Sagalowsky, MD, ${ }^{\mathrm{b}}$ David H. Rosenbaum, MD, ${ }^{\text {a }}$ Erkan Dikmen, MD, ${ }^{\mathrm{c}}$ Rehal A. Bhojani, BS, ${ }^{a}$ Michelle C. Paul, BS, ${ }^{a}$ Bart L. Dolmatch, MD, ${ }^{d}$ Shellie C. Josephs, MD, ${ }^{d}$ Elie A. Benaim, MD, ${ }^{b}$ Barry S. Levinson, MD, ${ }^{\mathrm{e}}$ Michael A. Wait, MD, ${ }^{a}$ W. Steves Ring, MD, ${ }^{a}$ and J. Michael DiMaio, MDa

From the Departments of Cardiovascular and Thoracic Surgery ${ }^{\mathrm{a}}$ and Urology, ${ }^{\mathrm{b}}$ the Department of Radiology, Division of Interventional Radiology, ${ }^{\mathrm{d}}$ and the Department of Internal Medicine, Division of Hematology-Oncology, ${ }^{\text {e }}$ University of Texas Southwestern Medical Center at Dallas, Dallas, Tex, and the Department of Thoracic Surgery, ${ }^{\mathrm{c}}$ Kirikkale University, Kirikkale, Turkey.

Supported in part by National Institutes of Health grant 5 T32 GM08593 for the Training Program in Burns, Trauma and Critical Care and the Donald W. Reynolds Cardiovascular Research Center.

Received for publication Oct 24, 2005; revisions received Jan 3, 2006; accepted for publication Jan 13, 2006.

Address for reprints: J. Michael DiMaio, MD, FACS, University of Texas Southwestern Medical Center at Dallas, 5323 Harry Hines Blvd, Dallas, TX 75390 (E-mail: michael. dimaio@utsouthwestern.edu).

J Thorac Cardiovasc Surg 2006;131:1289-95 $0022-5223 / \$ 32.00$

Copyright (C) 2006 by The American Association for Thoracic Surgery

doi:10.1016/j.jtcvs.2006.01.038
Objective: Renal cell carcinomas often form venous thrombi that extend into the vena cava. Frequently, cardiovascular consultation is necessary for complete surgical excision. We sought to investigate the risk factors, surgical techniques, and outcomes of patients treated for renal cell carcinoma with venous extension.

Methods: We reviewed the records of 46 consecutive patients who underwent surgical management of renal cell carcinoma with venous extension between 1991 and 2005. Data on patient history, staging, surgical techniques, morbidity, and survival were analyzed.

Results: There were 29 men and 17 women with a mean age of $60.2 \pm 12.0$ years. Twenty-five (54\%) procedures were completed with cardiovascular assistance. Nephrectomy was performed in $44(96 \%)$ cases. Three $(7 \%)$ patients underwent right heart venovenous bypass, and $2(5 \%)$ patients underwent cardiopulmonary bypass with circulatory arrest. Fourteen (32\%) patients had perioperative complications, including 1 (2\%) perioperative death. Patients who required cardiovascular procedures (inferior vena cava clamping, right heart venovenous bypass, and cardiopulmonary bypass with circulatory arrest) had higher risks of perioperative complications $(P<.02)$. The 1-, 2-, and 5-year overall survival rates were $78 \%$, $69 \%$, and $56 \%$.

Conclusions: This large series demonstrates that aggressive treatment of renal cell carcinoma with venous thrombus provides favorable outcomes. Our 5-year survival is among the highest of recent reviews, and our perioperative morbidity and mortality rates are comparable with those of other series. Tumors that require cardiovascular procedures are associated with increased complications when compared with radical nephrectomy and thrombectomy alone. Nevertheless, this aggressive treatment approach offers encouraging patient survival.

$\mathrm{R}$ enal cell carcinoma (RCC) is the most common renal neoplasm. Cancers of the kidney and renal pelvis are 12th among the leading causes of cancer deaths, accounting for 36,160 new diagnoses and 12,660 deaths in the United States in $2005 .^{1}$

Successful modern radical nephrectomy for the treatment of RCC was first reported in 1963. It involved removal of Gerota's fascia and its contents, including the kidney, adrenal gland, and perinephric adipose tissue. ${ }^{2}$ Today, the frequent use of abdominal imaging results in earlier diagnosis of smaller tumors that are frequently amenable to nephron-sparing surgery by means of open or laparoscopic techniques. ${ }^{3,4}$ For large tumors, laparoscopic radical nephrectomy and open radical nephrectomy are both considered the standard of care. ${ }^{5}$ 


\section{Abbreviations and Acronyms \\ IVC $=$ inferior vena cava \\ $\mathrm{RCC}=$ renal cell carcinoma}

Despite improvements in radiographic imaging and surgical techniques, RCC remains a technically challenging tumor to completely excise. This is attributed to its unique tendency for early extension into the renal veins and inferior vena cava (IVC). ${ }^{6}$ Tumor thrombus is present in up to $20 \%$ of patients presenting with RCC. . $^{72}$ The cephalad extent can range from the renal vein or IVC to the right atrium or proximal pulmonary artery. ${ }^{13}$ This extension dramatically increases the technical difficulty of safely removing the primary renal tumor and extracting the entire venous tumor thrombus.

Although an experienced urologist traditionally performs radical nephrectomy, occasionally multimodal techniques, such as liver mobilization, control of the vena cava, sternotomy, right heart venovenous bypass, and cardiopulmonary bypass with circulatory arrest, are necessary for safe and effective venous tumor thrombus extraction. ${ }^{14}$ This multimodal approach often involves cardiothoracic surgeons who have the benefit of extensive experience in the surgical management of the vena cava, heart, and thorax.

Although RCC with tumor thrombus presents as a challenging procedure for the surgeon, removal is the treatment of choice and results in increased disease-free survival. ${ }^{15}$ In an effort to further improve the treatment of this population, we analyzed patients who underwent surgical management of RCC with venous extension to assess risk factors, surgical techniques, and outcomes of their care.

\section{Patients and Methods}

We obtained institutional review board approval and retrospectively reviewed the medical records of 46 consecutive patients who presented with RCC with extension into the renal vein, IVC, or right atrium to the hospitals of the University of Texas Southwestern Medical Center at Dallas between April 1991 and April 2005. Data on patient demographics and history, clinical staging, surgical techniques, histopathologic staging, and perioperative morbidity and mortality were collected from medical records. Survival data were collected from follow-up records and office charts.

Several imaging modalities were used in the initial and follow-up care of these patients. The tumors were clinically staged by using abdominal and chest computed tomographic scans with other imaging techniques, including chest radiography. Magnetic resonance imaging was used in evaluation of the level of thrombus. Bone scans were used selectively in patients with large tumors or increased alkaline phosphatase levels. Additionally, positron emission tomography was used postoperatively for assessment of residual masses and restaging in follow-up care.

Tumor thrombus extension was classified according to 4 levels: level I, extension into the renal vein; level II, extension into the infrahepatic IVC; level III, IVC extension to the level of hepatic veins but below the diaphragm; and level IV, IVC extension above the diaphragm and into the right atrium or beyond. Bilateral tumors were classified according to the extent of the larger tumor. Pathologic and histologic stages were assigned according to the 2002 TNM staging system and Fuhrman classification, respectively. ${ }^{16,17}$

Preoperative renal artery alcohol angioembolization was performed to facilitate arterial vascular control in patients with bulky tumor thrombus, hilar adenopathy, or hypervascularity.

Radical nephrectomy (removal of Gerota's fascia and its contents, including the kidney, ipsilateral adrenal gland, and perinephric adipose tissue) with removal of the tumor thrombus and regional lymphadenectomy was attempted in all patients.

Cardiovascular procedures, such as IVC clamping, right heart venovenous bypass, and cardiopulmonary bypass with circulatory arrest, were available to aid in venous tumor thrombus extraction. The latter 2 procedures were reserved for patients who could not tolerate IVC clamping or whose tumors extended into the right atrium or beyond.

Perioperative complications within the first 30 days of the postoperative period included hemorrhage and coagulopathy, pleural effusion, pneumothorax, prolonged ileus (for $>4$ days), poor nutritional intake, nausea and vomiting, pancreatitis, deep venous thrombosis, splenectomy, acute respiratory distress syndrome, neurologic dysfunction, renal failure, pulmonary failure, and death.

Survival time was calculated from the date of the operation to the date of last contact or date of death. Three patients who were lost to follow-up were excluded from the survival analysis. The cumulative survival rates were calculated by using Kaplan-Meier analysis, and the significance was determined by using the logrank test. Categorical variables were analyzed with the $\chi^{2}$ and Fisher exact tests as appropriate in contingency tables, whereas the Student $t$ test and Mann-Whitney $U$ test were performed as appropriate for comparison of continuous variables. The logistic regression model was applied for univariate analysis to confirm determining factors of complications. Data were expressed as means \pm 1 standard deviation unless specified otherwise. All statistical analyses were performed with the Statistical Package for Social Sciences (SPSS; version 12.0, Chicago, Ill).

\section{Results}

\section{Clinical Features}

Although this study encompasses a 14-year period, 19 (41.3\%) of the patients were treated during the last 2 years of data collection. All tumors were classified clinically as either T3b or T3c at the time of diagnosis by using the 2002 TNM staging system. ${ }^{16}$ Patient demographics and clinical characteristics are shown in Table 1.

Patients presented asymptomatically or with varying symptoms of hematuria, ipsilateral flank pain, weight loss, lower extremity swelling, change in appetite, feeling of fullness, or distended subcutaneous veins. Tumors were localized in the right kidney of $30(65 \%)$ patients and the left kidney of the other $16(35 \%)$ patients. Six (13\%) patients presented with distant metastases, with the most common site of metastasis being the lung $(\mathrm{n}=6)$. Three $(7 \%)$ patients presented with lymphadenopathy. Mean clinical tumor size 
TABLE 1. Patient demographics and clinical characteristics

\begin{tabular}{lc} 
Age ${ }^{*}, y$ & $60.2 \pm 12.0$ \\
Sex & \\
Male & $29(63 \%)$ \\
Female & $17(37 \%)$ \\
Race or ethnic group & \\
White & $33(72 \%)$ \\
Hispanic & $7(15 \%)$ \\
Black & $5(11 \%)$ \\
Other & $1(2 \%)$ \\
Presenting symptoms & \\
Hematuria & $29(63 \%)$ \\
Flank pain & $23(50 \%)$ \\
Weight loss & $11(24 \%)$ \\
Asymptomatic & $10(22 \%)$ \\
Lower extremity swelling & $4(9 \%)$ \\
Change in appetite & $2(4 \%)$ \\
Feeling of fullness & $2(4 \%)$ \\
Distended subcutaneous veins & $1(2 \%)$ \\
\hline
\end{tabular}

Data are presented as the numbers of patients $(\%)$ unless otherwise specified. *Mean \pm 1 standard deviation.

was $9.7 \pm 3.8 \mathrm{~cm}$ (range, $4.8-20.0 \mathrm{~cm}$ ). Eleven (24\%) patients had a level I, 16 (35\%) had a level II, $15(33 \%)$ had a level III, and 4 (9\%) had a level IV venous tumor thrombus (Figure 1).

\section{Surgical Intervention}

Of the 46 patients who presented with RCC with tumor thrombus in this study, 40 (87\%) had complete tumor removal, including 39 with radical nephrectomy and tumor thrombectomy and 1 partial nephrectomy and complete thrombectomy in a patient with a solitary kidney. Of the remaining patients, 4 (9\%) had successful radical nephrectomy with incomplete tumor thrombectomy caused by extensive intraoperative hemorrhage $(\mathrm{n}=1)$, widespread lymph node $(\mathrm{n}=1)$ or liver $(\mathrm{n}=1)$ metastases, or growth into the posterior body wall and liver $(n=1)$. Two of these patients underwent second procedures, and subsequent thrombectomy was successful in 1 patient. Nephrectomy was not performed in the remaining $2(4.3 \%)$ of the total 46 patients because of intraoperative findings of liver cirrhosis or tumor extension into the posterior body wall in 1 patient each. These final 2 patients were omitted from further statistical analysis.

Thirteen patients underwent preoperative renal artery alcohol angioembolization. Lymphadenectomy was performed in 39 (89\%) patients, with a mean of $7 \pm 6$ nodes (range, 1-26 nodes) removed. Ipsilateral adrenalectomy was performed in 35 (80\%) patients.

Cardiovascular procedures, such as IVC clamping, right heart venovenous bypass, and cardiopulmonary bypass with circulatory arrest, were performed in 29 (66\%) patients. IVC clamping was the most common cardiovascular proce-

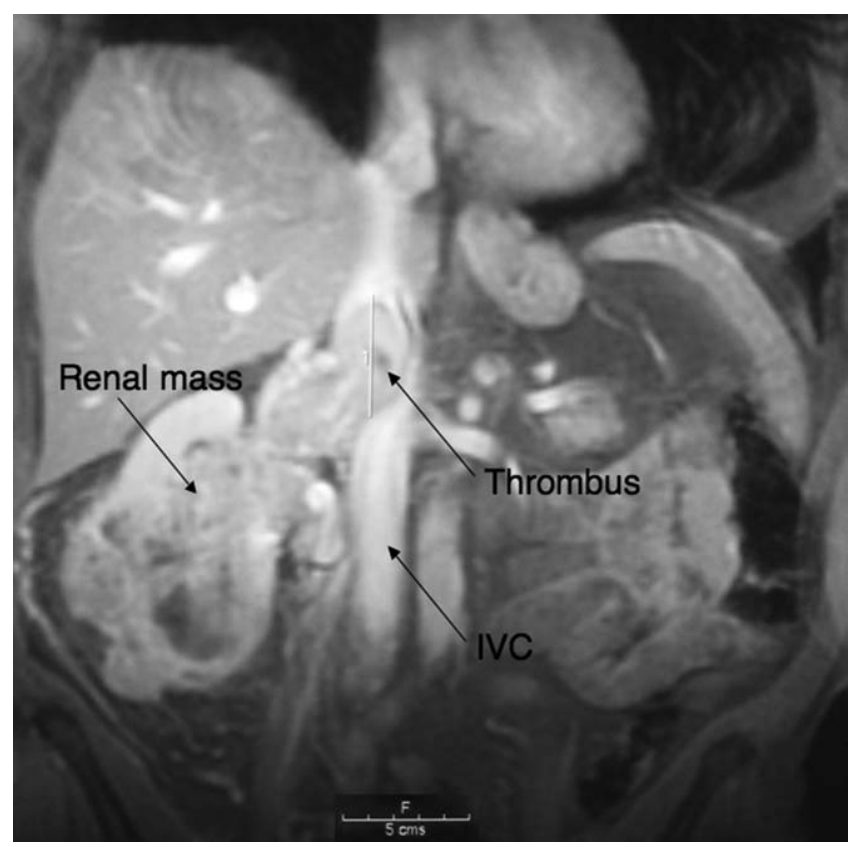

Figure 1. Magnetic resonance image of a patient with renal cell carcinoma who presented with a level II venous tumor thrombus (extension into the infrahepatic inferior vena cava [IVC]).

dure, performed in 24 patients. Venovenous bypass was performed in 3 patients, and cardiopulmonary bypass with circulatory arrest was performed in 2 patients. See Table 2 for surgical descriptions by thrombus level.

\section{Level I Thrombi}

Eleven patients were found to have a thrombus in the renal vein. No patients in this group received preoperative renal artery alcohol angioembolization or cardiovascular consultation during nephrectomy. Negative surgical margins were reported in $9(82 \%)$ patients. Of the 2 patients with positive surgical margins, one had a section of metastatic adrenal gland attached to the liver and IVC, and the other had an adherent lymph node package that could not be entirely removed. Three $(27 \%)$ patients in this group were treated postoperatively with immunotherapy.

\section{Level II Thrombi}

Fifteen patients were operated on with a thrombus extending into the infrahepatic IVC. Seven patients had preoperative renal artery alcohol angioembolization. IVC clamping was necessary in 14 patients. A cardiothoracic surgeon assisted in $8(53 \%)$ operations. In all but 2 cases (87\%), the surgical margins were negative. One patient had a metastatic adrenal gland adherent to the liver, and the second patient had metastatic adhesions infiltrating the posterior 
TABLE 2. Surgical characteristics by tumor thrombus level

\begin{tabular}{|c|c|c|c|c|c|}
\hline Characteristic & Total & Level I & Level II & Level III & Level IV \\
\hline Patients & $44(100 \%)$ & $11(25 \%)$ & $15(34 \%)$ & $14(32 \%)$ & $4(9 \%)$ \\
\hline Angioembolization & $13(30 \%)$ & 0 & $7(47 \%)$ & $5(36 \%)$ & $1(25 \%)$ \\
\hline \multicolumn{6}{|l|}{ Operation } \\
\hline Radical nephrectomy & $43(98 \%)$ & $10(91 \%)$ & $15(100 \%)$ & $14(100 \%)$ & $4(25 \%)$ \\
\hline Imperative NSS & $1(2 \%)$ & $1(9 \%)$ & 0 & 0 & 0 \\
\hline \multicolumn{6}{|l|}{ Incision type } \\
\hline Transverse chevron & $35(80 \%)$ & $9(82 \%)$ & $14(93 \%)$ & $9(64 \%)$ & $3(75 \%)$ \\
\hline Midline & $6(14 \%)$ & 0 & 0 & $5(36 \%)$ & $1(25 \%)$ \\
\hline Flank & $2(5 \%)$ & $2(18 \%)$ & 0 & 0 & 0 \\
\hline Thoracoabdominal & $1(2 \%)$ & 0 & $1(7 \%)$ & 0 & 0 \\
\hline Procedure duration, min & $390(185-700)$ & $320(200-465)$ & $350(185-590)$ & $460(300-700)$ & $460(395-570)$ \\
\hline IVC clamping & $24(55 \%)$ & 0 & $14(93 \%)$ & $10(71 \%)$ & 0 \\
\hline Clamp time, $\min$ & $31(3-69)$ & - & $21(3-37)$ & $34(20-69)$ & - \\
\hline Right heart venovenous bypass & $3(7 \%)$ & 0 & 0 & $3(21 \%)$ & 0 \\
\hline Clamp time, $\min$ & $33(23-41)$ & - & - & $33(23-41)$ & - \\
\hline Pump time, min & $67(43-204)$ & - & - & $67(43-204)$ & - \\
\hline Cardiopulmonary bypass & $2(5 \%)$ & 0 & 0 & 0 & $2(50 \%)$ \\
\hline Bypass time, min & $92(89-95)$ & - & - & - & $92(89-95)$ \\
\hline Aortic crossclamp time, min & $46(46)$ & - & - & - & $46(46)$ \\
\hline Circulatory arrest time, min & $15(10-19)$ & - & - & - & $15(10-19)$ \\
\hline $\mathrm{EBL}, \mathrm{L}$ & $3.0(0.4-30.0)$ & $1.7(0.4-4.5)$ & $2.5(0.5-16.5)$ & $5.1(0.8-30.0)$ & $1.6(1.2-1.8)$ \\
\hline
\end{tabular}

Data are presented as the number of patients (\%) or the mean value (range) unless otherwise specified. Angioembolization, Preoperative renal artery alcohol angioembolization; NSS, nephron-sparing surgery; IVC, inferior vena cava; Cardiopulmonary bypass, cardiopulmonary bypass with circulatory arrest; $E B L$, estimated blood loss.

body wall. Successful vena caval thrombectomy was achieved in all patients $(100 \%)$. The only perioperative death in this series was a 79-year-old man with a history of congestive heart failure who died on the first postoperative day of intraoperative hemorrhage resulting from extensive invasion of the tumor into the posterior body wall and diaphragm, followed by ongoing coagulopathy. One (7\%) patient received preoperative immunotherapy because of extensive metastatic disease. This patient, along with $3(27 \%)$ others, received immunotherapy postoperatively. One (7\%) patient received postoperative chemotherapy.

\section{Level III Thrombi}

Fourteen patients had a tumor thrombus extending into the IVC behind the liver but below the diaphragm. Of these 14 patients, 5 underwent preoperative renal artery alcohol angioembolization. A cardiothoracic team was present for 13 (93\%) of the cases in this group. IVC clamping was used for 10 patients. Suprahepatic control of the IVC and control of the porta hepatis were routinely gained when attempting tumor thrombectomy. In 3 patients who were hemodynamically unstable during the initial cross-clamping of the IVC, right heart venovenous bypass was used to assist in removal of the thrombus. In the majority of patients in this series, the tumor thrombi were free flowing within the lumen of the IVC. At points of adherence, when present, attempts were made to bluntly dissect the thrombus free of the caval wall.
In the few cases in which small parts of thrombus were attached to the caval wall, the small part of the IVC wall that had adherent thrombus, when safe, was removed. Although negative surgical margins of the primary tumor were reported in all patients (100\%) in this group, the caval portion of the venous tumor thrombus was initially left intact in 2 patients: one because of extensive growth into the posterior body wall and liver and the other because of intraoperative coagulopathy. After 6 months of systemic therapy, the latter patient underwent successful vena caval thrombectomy in May 2005 and at last follow-up was disease free and clinically well. Four (29\%) patients were treated postoperatively with immunotherapy. Postoperative radiation was given to $3(21 \%)$ patients in this group, and $2(14 \%)$ patients were treated with chemotherapy.

\section{Level IV Thrombi}

Four patients had a thrombus that extended above the diaphragm, with or without extension into the right atrium. One patient received preoperative renal artery alcohol angioembolization. A cardiothoracic surgeon assisted in all 4 procedures $(100 \%)$. Two patients required cardiopulmonary bypass with circulatory arrest. Negative surgical margins of the primary tumor were reported in all 4 patients $(100 \%)$. The caval tumor thrombus was left intact in 2 patients. In 1 patient nephrectomy was performed, but 2 large metastatic lymph node packets were found intraoperatively that were 
TABLE 3. TNM ${ }^{16}$ tumor staging profiles

\begin{tabular}{lr}
\hline Classification & \\
\hline T (tumor) & $30(68 \%)$ \\
T3b & $6(14 \%)$ \\
T3c & $8(18 \%)$ \\
T4 & \\
N (node) & $6(14 \%)$ \\
Nx & $30(68 \%)$ \\
N0 & $5(11 \%)$ \\
N1 & $3(7 \%)$ \\
N2 & \\
M (metastasis) & $35(80 \%)$ \\
M0 & $9(20 \%)$ \\
M1
\end{tabular}

Data are presented as the number of patients $(\%)$.

adherent to the vena cava. These prevented complete tumor thrombus extraction and caval reconstruction. This patient received prolonged interferon therapy, remained free of distal tumor progression, and underwent a second operation in which necrotic retroperitoneal lymph nodes were removed. He continued to take interferon $\alpha$ until associated cardiomyopathy required discontinuation. At 46 months postoperatively, this patient was clinically well but showed signs of tumor progression with an enlarged IVC thrombus and IVC occlusion. This demonstrates that patients are living longer, even with advanced disease. At the time of last follow-up, this patient was scheduled to resume immunotherapy. The second patient had extensive liver metastases, which contraindicated thrombus removal. Only 1 (25\%) patient in this group received postoperative immunotherapy.

\section{Postoperative Care}

Patients spent a median of $2.0 \pm 11.9$ days (range, 0.5-71 days) in the intensive care unit, and median total length of stay was $8 \pm 11$ days (range, 1-71 days).

\section{Histopathology}

On gross and microscopic evaluation, 15 (34\%) patients had tumors that were fully contained within the renal capsule. The mean pathologic tumor size was $10.3 \pm 3.9 \mathrm{~cm}$ (range, 4.7-20.0 cm). There were no patients with tumors of Fuhrman nuclear grade I, 17 (39\%) with tumors of grade II, 17 (39\%) with tumors of grade III, and $10(23 \%)$ with tumors of grade IV. Thirty-six (82\%) patients had tumors of the clear cell type, $5(11 \%)$ had tumors with a sarcomatoid pattern, $2(5 \%)$ had tumors with a granular pattern, and 1 (2\%) had a tumor with a papillary component. See Table 3 for TNM tumor staging profiles.

\section{Complications and Survival}

Nineteen postoperative complications occurred in 14 (32\%) patients, including $1(2 \%)$ perioperative death on the first

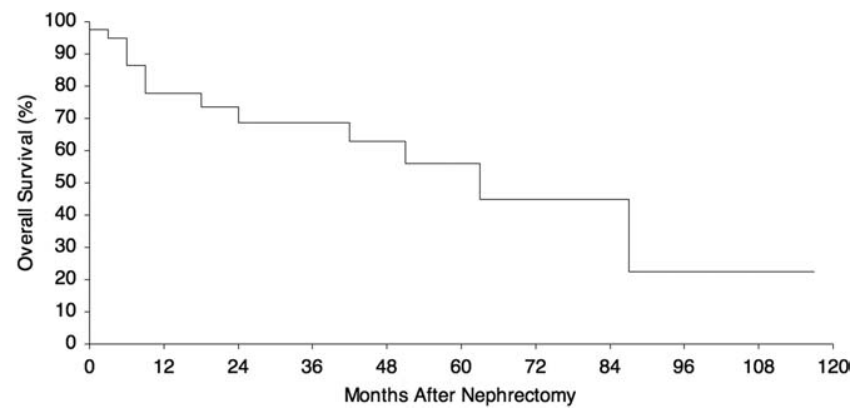

Figure 2. Kaplan-Meier estimates of overall survival of patients with renal cell carcinoma with venous tumor thrombus.

postoperative day caused by coagulopathy. The most common intraoperative and postoperative complications were prolonged ileus $(\mathrm{n}=5,11 \%)$, deep venous thrombosis $(\mathrm{n}=$ $3,7 \%)$, pleural effusion $(\mathrm{n}=2,5 \%)$, and splenectomy $(\mathrm{n}=$ $2,5 \%)$.

The presence of a perioperative complication did not correlate with mean age $(P=.68)$, age subgroups $(P=.33)$, sex $(P=.51)$, smoking history $(P=.20)$, preoperative American Society of Anesthesiologists class $(P=.18)$, preoperative renal artery alcohol angioembolization $(P=$ $.12)$, or mean duration of the operation $(P=.30)$. However, patients requiring intraoperative cardiovascular procedures had greater complication rates than patients without $(P<$ $.02)$.

At the time of the last follow-up, 26 patients were alive, and 14 were reported deceased, with a mean follow-up time of 26 months. The mean survival of patients was $63.5 \pm 9.5$ months (median, 64 months; range, 2-117 months; Figure 2). The 1-, 2-, and 5-year survival rates were 78\%, 69\%, and $56 \%$, respectively. These favorable results are among the highest long-term survival rates reported by any recent comparable series (Table 4). ${ }^{7,12,18-21}$

No significant survival differences were observed regarding age subgroups $(P=.93)$, preoperative renal artery alcohol angioembolization $(P=.99)$, tumor status $(P=$ $.55)$, the presence of lymph node metastasis $(P=.30)$, or the presence of distant metastasis $(P=.85)$. Additionally, there was no significant survival difference between the patients with TNM stage III and stage IV disease $(P=.96)$.

In univariate analysis, by using the logistic regression model, patients who required cardiovascular procedures (IVC clamping, right heart venovenous bypass, or cardiopulmonary bypass with circulatory arrest) had an approximately 4-fold increased risk of complication $(P=.11)$. In addition, patients with level III and level IV thrombi had an approximately 2-fold increased risk of complication versus patients with level I and II thrombi $(P=.28)$. 
TABLE 4. Complication and survival rates in recent series

\begin{tabular}{|c|c|c|c|c|c|c|}
\hline \multirow[b]{2}{*}{ Series } & \multirow[b]{2}{*}{ Patients } & \multirow[b]{2}{*}{ 5-y survival } & \multirow[b]{2}{*}{ Comp } & \multicolumn{2}{|c|}{ Deaths } & \multirow[b]{2}{*}{ Years } \\
\hline & & & & Intraoperative & Perioperative & \\
\hline Blute and coworkers ${ }^{18}$ & 540 & $44.4 \%$ & $11 \%$ & $1.3 \%$ & $1.9 \%$ & $1970-2000$ \\
\hline Goetzl and coworkers ${ }^{19}$ & 56 & $4 \%$ & $14 \%$ & 0 & $1.8 \%$ & 1989-2003 \\
\hline Jibiki and coworkers ${ }^{20}$ & 31 & $42 \%$ & $35 \%$ & $3.2 \%$ & 0 & $1980-2001$ \\
\hline Nesbitt and coworkers ${ }^{7}$ & 37 & $33.6 \%$ & $30 \%$ & 0 & $2.7 \%$ & 1989-1996 \\
\hline Sweeney and coworkers ${ }^{12}$ & 96 & $35 \%$ & $38 \%$ & 0 & $5.2 \%$ & 1985-2001 \\
\hline Tsuji and coworkers ${ }^{21}$ & 33 & $44 \%$ & - & 0 & $6.1 \%$ & 1983-1999 \\
\hline Current series & 44 & $56 \%$ & $32 \%$ & 0 & $2.3 \%$ & $1991-2005$ \\
\hline
\end{tabular}

All series include patients with preoperative metastatic disease. Patients, Number of patients in statistical analyses; Comp, perioperative complication rate; Intraoperative, intraoperative mortality rate; Perioperative, perioperative mortality rate; - , data not reported.

\section{Discussion}

Up to $20 \%$ of patients with RCC have tumor extension into the venous system on presentation. ${ }^{7-12}$ The tumor thrombus can extend into the renal vein (level I), the IVC below the liver (level II), the IVC behind the liver and up to the diaphragm (level III), and above the diaphragm and into the right atrium (level IV). It has even been reported that tumor thrombi can extend as far cephalad as the pulmonary artery. ${ }^{13}$

Considerable advances have been made in the management of a tumor thrombus. These include the use of new diagnostic imaging modalities to define its level, as well as the use of extracorporeal bypass to permit safe surgical resection. ${ }^{12}$ Additionally, several studies demonstrate that combined aggressive surgical intervention and postoperative immunotherapy have a positive influence on long-term survival in patients with conventional (clear cell) RCC, the most prevalent subtype. ${ }^{22-25}$

Preoperative renal artery alcohol angioembolization was used more frequently in the most recent cases of this series, with $85 \%(\mathrm{n}=11)$ of the procedures performed in the last 15 months of data collection. We performed this procedure 1 day before surgical intervention to diminish intraoperative bleeding. Several disadvantages of this procedure include the cost of the procedure, the extra day in the hospital, and morbidity, such as flank pain and toxicity from renal infarction.

Although higher levels of tumor thrombi constitute greater surgical difficulty and risk, the stage of the primary tumor and lymph node status remain the main determinants of prognosis. ${ }^{7,9,11,14,21}$ There is no evidence that the presence of tumor thrombus alone is a detriment to survival. ${ }^{8}$ However, untreated venous tumor thrombi might result in acute pulmonary emboli with sudden fatal outcomes. Aggressive resection of the primary tumor and associated tumor thrombus offers the highest patient survival.

In a recent series Sweeney and associates ${ }^{12}$ reported that there was a significant decrease in long-term survival in patients with lymph node metastases. On the other hand, they did not observe a statistically significant difference in survival on the basis of distant metastasis. Tsuji and colleagues ${ }^{21}$ reported similar results according to lymph node metastasis and distant metastasis. Findings from our series regarding the effect of each of these factors (lymph node and metastasis status) were consistent with these reports, but our data regarding lymph node status did not reach statistical significance because of limitations in sample size.

Radical nephrectomy and tumor thrombectomy require adequate control of bleeding. This was achievable in most cases with control of the renal vein and IVC alone, but specific intraoperative cardiovascular procedures were used depending on the cephalad extent of the thrombus. Nephrectomy was performed without any additional vascular procedures in patients with level I thrombi. When the tumor thrombus was localized within the infrahepatic IVC, extraction was usually achieved by means of IVC clamping. Caval exposure might or might not have required sternotomy. When the tumor thrombus extended into the IVC behind the liver or higher, exposure and isolation of the IVC were more extensive. That often required mobilization of the liver with or without the use of right heart venovenous bypass or cardiopulmonary bypass and deep hypothermic circulatory arrest. Right heart venovenous bypass added a measure of cardiac stability in hemodynamically unstable patients during caval clamping. Cardiopulmonary bypass with circulatory arrest was reserved for patients with the most extensive intracardiac thrombi. Cardiothoracic surgeons offered the most complete range of operative techniques that were necessary depending on the full extent of the intraoperative findings or when the patient response to IVC clamping required sternotomy, right heart venovenous bypass, or complete cardiopulmonary bypass with circulatory arrest. However, in many cases a liver transplant or vascular surgeon could have provided the requisite skills for caval thrombectomy.

Nineteen postoperative complications occurred in 14 patients, but there were no intraoperative deaths. Only $1(2 \%)$ perioperative death occurred. The 1-, 2-, and 5-year survival rates were $78 \%, 69 \%$, and $56 \%$, respectively. These favor- 
able results are among the highest survival rates in comparable recent series and can be attributed to the aggressive treatment strategy taken with careful attention to vascular control (Table 4).

Radical nephrectomy and thrombectomy offers an effective option for patients with kidney tumors and tumor thrombi. Despite the increased risk of perioperative complications associated with the use of cardiovascular procedures, an aggressive approach does not negatively affect long-term survival, even in the presence of metastatic disease. A multidisciplinary approach, including urology, interventional radiology, and cardiothoracic surgery, provides optimal results.

The conclusions are limited by several characteristics of this study. These include the retrospective and uncontrolled nature of this series, that it is based on a single institution's experience, and the relatively small sample size of the studied patient population. Despite these reservations, this report is based on enough patients to provide an adequate conclusion and represents our ongoing cumulative experience with an increasing rate of referral of patients with this surgically challenging disease.

We thank Jesse Williams and Connie Smith for their assistance with patient follow-up and medical record data collection.

\section{References}

1. Jemal A, Murray T, Ward E, Samuels A, Tiwari RC, Ghafoor A, et al. Cancer statistics, 2005. CA Cancer J Clin. 2005;55:10-30.

2. Robson CJ. Radical nephrectomy for renal cell carcinoma. J Urol. 1963;89:37-42.

3. Butler BP, Novick AC, Miller DP, Campbell SA, Licht MR. Management of small unilateral renal cell carcinomas: radical versus nephronsparing surgery. Urology. 1995;45:34-40.

4. Uzzo RG, Novick AC. Nephron sparing surgery for renal tumors: indications, techniques and outcomes. J Urol. 2001;166:6-18.

5. Ono Y, Hattori R, Gotoh M, Yoshino Y, Yoshikawa Y, Kamihira O. Laparoscopic radical nephrectomy for renal cell carcinoma: the standard of care already? Curr Opin Urol. 2005;15:75-8.

6. Novick AC, Campbell SC. In: Walsh PC, Retik AB, Vaughn ED Jr, Wein AS, editors. Campbell's urology. Vol 4. 8th ed. Philadelphia: W.B. Saunders; 2002. p. 2672-731.

7. Nesbitt JC, Soltero ER, Dinney CP, Walsh GL, Schrump DS, Swanson DA, et al. Surgical management of renal cell carcinoma with inferior vena cava tumor thrombus. Ann Thorac Surg. 1997;63:1592-600.

8. Hatcher PA, Anderson EE, Paulson DF, Carson CC, Robertson JE. Surgical management and prognosis of renal cell carcinoma invading the vena cava. J Urol. 1991;145:20-3.
9. Hoehn W, Hermanek P. Invasion of veins in renal cell carcinomafrequency, correlation and prognosis. Eur Urol. 1983;9:276-80.

10. Marshall VF, Middleton RG, Holswade GR, Goldsmith EI. Surgery for renal cell carcinoma in the vena cava. J Urol. 1970;103:414-20.

11. Ljungberg B, Stenling R, Osterdahl B, Farrelly E, Aberg T, Roos G. Vein invasion in renal cell carcinoma: impact on metastatic behavior and survival. $J$ Urol. 1995; 154:1681-4.

12. Sweeney P, Wood CG, Pisters LL, Slaton JW, Vaporciyan A, Munsell $\mathrm{M}$, et al. Surgical management of renal cell carcinoma associated with complex inferior vena caval thrombi. Urol Oncol. 2003;21:327-33.

13. Wieder JA, Laks H, Freitas D, Marmureanu A, Belldegrun A. Renal cell carcinoma with tumor thrombus extension into the proximal pulmonary artery. J Urol. 2003;169:2296-7.

14. Vaidya A, Ciancio G, Soloway M. Surgical techniques for treating a renal neoplasm invading the inferior vena cava. J Urol. 2003;169: 435-44.

15. Curti BD. Renal cell carcinoma. JAMA. 2004;292:97-100.

16. Green FL, Page DL, Fleming ID, Fritz A, Balch CM, Haller DG, et al, editors. AJCC cancer staging manual. 6th ed. New York: SpringerVerlag; 2002.

17. Fuhrman SA, Lasky LC, Limas C. Prognostic significance of morphologic parameters in renal cell carcinoma. Am J Surg Pathol. 1982;6: 655-63.

18. Blute ML, Leibovich BC, Lohse CM, Cheville JC, Zincke H. The Mayo Clinic experience with surgical management, complications and outcome for patients with renal cell carcinoma and venous tumour thrombus. BJU Int. 2004;94:33-41.

19. Goetzl MA, Goluboff ET, Murphy AM, Katz AE, Mansukhani M, Sawczuk IS, et al. A contemporary evaluation of cytoreductive nephrectomy with tumor thrombus: morbidity and long-term survival. Urol Oncol. 2004;22:182-7.

20. Jibiki M, Iwai T, Inoue $\mathrm{Y}$, Sugano N, Kihara K, Hyochi N, et al. Surgical strategy for treating renal cell carcinoma with thrombus extending into the inferior vena cava. J Vasc Surg. 2004;39:829-35.

21. Tsuji Y, Goto A, Hara I, Ataka K, Yamashita C, Okita Y, et al. Renal cell carcinoma with extension of tumor thrombus into the vena cava: surgical strategy and prognosis. J Vasc Surg. 2001;33:789-96.

22. Swierzewski DJ, Swierzewski MJ, Libertino JA. Radical nephrectomy in patients with renal cell carcinoma with venous, vena caval, and atrial extension. Am J Surg. 1994;168:205-9.

23. Mickisch GH, Garin A, van Poppel H, de Prijck L, Sylvester R, European Organisation for Research and Treatment of Cancer (EORTC) Genitourinary Group. Radical nephrectomy plus interferon-alfa-based immunotherapy compared with interferon alfa alone in metastatic renal-cell carcinoma: a randomised trial. Lancet. 2001;358:966-70.

24. Flanigan RC, Salmon SE, Blumenstein BA, Bearman SI, Roy V, McGrath PC, et al. Nephrectomy followed by interferon alfa-2b compared with interferon alfa- $2 b$ alone for metastatic renal-cell cancer. N Engl J Med. 2001;345:1655-9.

25. Naitoh J, Kaplan A, Dorey F, Figlin R, Belldegrun A. Metastatic renal cell carcinoma with concurrent inferior vena caval invasion: long-term survival after combination therapy with radical nephrectomy, vena caval thrombectomy and postoperative immunotherapy. J Urol. 1999; 162:46-50. 